\title{
The present shock and time re-appropriation: rethinking science education in the pandemic era
}

\author{
Olivia Levrini (*), Paola Fantini (*), Eleonora Barelli (*), \\ Laura Branchetti (**), Sara Satanassi $(*)$, Giulia Tasquier (*)
}

(*) Department of Physics and Astronomy, Alma Mater Studiorum - University of Bologna, Italy (**) Department of Mathematical, Physical and Computer Sciences, University of Parma, Italy

\begin{abstract}
The crisis due to the COVID-19 pandemic is so huge that raises enormous questions about its implications for our societies and personal lives. In this article, we focus on science education and the role it can play to prepare future generations to grapple with this complex, fastchanging and fragile society. The approach we chose is centered on the concept of time, whose perception and organisation has been deeply affected by pandemic-induced changes. An exploratory qualitative study has been carried out with secondary school students to investigate how they were experiencing time during lockdown and which (if any) scientific knowledge they were activating to grapple with the current uncertainty and change in time structures.

The main result concerns the discovery of the potential of the dichotomy between alienation from time and time re-appropriation to highlight the difference between future shock, (characteristic of the pre-crisis society of acceleration) and present shock (characteristic of the pandemic era). The analysis of students' interviews allowed us to start unpacking time re-appropriation and its links with science learning and identity development.

On the basis of the analysis, we identified three directions that science education research could explore to support schools and science teaching in playing a leading role in this fast-changing society. The directions concern new thematic and epistemological priorities for science curricula, new emphasis on learning and teaching rituals fostering appropriation, and arguments for revising the institutional role of schools.
\end{abstract}

\section{Introduction}

We are experiencing an extraordinary period, during which many parts of the world are locked down due to the coronavirus infection.

This is a time where people are grappling with different forms of grief or suffering and professionals are reflecting on the impacts of this crisis on their work and societal roles.

This crisis also impacts the very heart of science education, raising foundational questions: To what extent will science education be affected by this pandemic? What contribution can science education provide to understand and address global crises like this? Even more fundamentally, what is the sense and role of our research field in the current fragile, fast-changing and global society?

This paper aims to respond to the challenge launched by Science \& Education journal and tries to offer a perspective to critically reflect on science and STEM curricula. In particular, we took the opportunity provided by the quarantine period to re-analyse the research perspective we have been developing over the last 15 years and test its significance against the new challenges. The analysis was carried out to highlight both its limitations and potential to "prepare the future generations for acquiring knowledge and skills to deal with global concerns such as pandemics and the climate emergency" (Erduran, 2020). 
From the analysis, a list of new questions has been drawn up as possible starting points to align the science education research agenda and priorities with the current times.

The paper is articulated as follows.

In Section 2 our research perspective is presented and framed in the literature. Specifically, we introduce the core concepts that have guided our approach: the notions of "future shock" (Toffler \& Toffler, 1970) and of "present shock", which, as we will argue, characterises the time structure of the pandemic era. Their comparison will allow us to reflect on which skills are needed to manage, rationally and emotionally, their intertwining and what could be the role of science education in helping secondary school students to deal with time in our society of acceleration and uncertainty (Rosa, 2010).

Then, we move on to the qualitative study with secondary school students, which we carried out to investigate how they were experiencing time in this period and which (if any) scientific knowledge they were activating to grapple with the current uncertainty. Before presenting the specific goals, the sample, the methods, and the results of the study (Section 4), we describe previous investigations that represent the background to the study (Section 3).

To introduce the argumentation flow, we wish to stress the main idea of the paper, borrowed from the field of "sociology of time" and elaborated through the lens of science education. This idea is the following.

As well as being a scientific, anthropological, and psychological construct, time can also be a sociological perspective, investing social forms and structures (Cavalli, 1985). In fact, social actions and interactions, cultures, institutional and power dynamics can be analysed for their temporal structures, like rituals, images of the futures, relations with the past (Rosa, 2010). Furthermore, social transformations can be understood by zooming in on individuals and how they perceive, represent, experience and re-elaborate time (Leccardi, 2009). Time perspective, from a sociological perspective, is a multiform lens that keeps together different scales, from the individual micro-cosmos to the social macro-cosmos that retroact on each other (Rosa, 2010).

Very often these time structures are invisible, taken for granted, made trivial by habits and routines. Only in some historical moments do they emerge: one of these occasions is the pandemic era, when global time is accelerated by a natural phenomenon (the virus evolution); social institutions (policy, health systems, educational systems, economics) try to run as quickly as possible to slow down the epidemic velocity; and individual time is suspended in a bubble of present (a period of waiting).

During this period, the dynamics - and inner velocities - of natural phenomena, social practices, biological and cultural needs, daily rituals, inter-subjective and affective relationships are unveiled and we tend to feel a deep sense of disruption due to their emergence. We will call this feeling "present shock" and, in this paper, we will try to describe it in comparison with the much betterknown phenomenon defined by sociologists as "future shock". More relevantly for our research field, we will try to argue why it is important to conceptualise this idea of present shock in our contemporary societies, and how science education can contribute to developing knowledge and skills to deal with such fast-changing time structures. 
Paper submitted to Science \& Education

\section{Framework}

\section{1 "Future shock" and the society of acceleration}

The term "future shock" was coined by Alvin and Heidi Toffler in their 1970 book.

Future shock indicates a certain psychological state that individuals and entire societies experience when they perceive "too much change in too short a period of time". Although introduced in the early Seventies, future shock was widely perceived more recently. In particular, it can be used to characterise what the German sociologist Harmut Rosa calls the "society of acceleration" (Rosa, 2009; 2010; 2013).

According to Rosa's analysis, modern life is subject to three major dimensions of acceleration: (i) technical acceleration, (ii) social acceleration, i.e. changes in the institutions through which we bring order to our lives and (iii) acceleration in the pace of life, i.e. the general sense and experience of time and deadlines on a day-to-day basis (Rosa, 2010; 2013).

Technical acceleration is central to Rosa's argument and is indicated as the main driver. Indeed, in contemporary societies, humans do not often interface directly with the natural world: they live in a techno-ecology. It is such techno-ecology that, in contemporary societies, mainly drives (and accelerates) global dynamics.

Another central issue of Rosa's argument is that social institutions, like political and educational systems, despite changing, are not able to keep up with the pace of technological transformation. Because of their inertia, things seem to change very quickly but, in fact, they happen without any strong sense of directionality. This perspectiveless state leads to what is called 'frenetic standstill'. Events remain episodic in both individual and collective experience and, because of the lack of directionality, "nothing remains the same but nothing essentially changes" (Rosa, 2013, loc. 7100). The impact of frenetic standstill on individuals appears as a sense of fragmentation or dispersion of the sense of self (Giddens, 1991; Gee, 2001; Bauman, 2000; Bauman 2001). Following Rosa's argument, identity become situational:

"The individual's reaction to social acceleration [...] seems to result in a new, situational form of identity, in which the dynamism of classical modernity, characterised by a strong sense of direction (perceived as progress), is replaced by a sense of directionless, frantic motion that is in fact a form of inertia" (Rosa, 2009; p.101).

On encountering such a sentence, no-one, especially those who care about education, can remain indifferent. Indeed, we have all been surrounded by this imperceptible feeling of breathlessness, disorientation and disharmony caused by the coexistence of different misaligned times. On one hand, we have the time we need for reflection, taking care of ourselves and people around us, learning, figuring out solutions for pursuing social equity, or addressing global challenges like climate change. On the other hand, we see the world running, innovating, competing, exchanging at an impressive velocity, creating continuously new and unpredictable scenarios and needs that leave behind all other requirements. This misalignment leads to a sense of fragmentation in our experiences that can lead to frustration but also forms of burnout.

To describe this fragmented and meaningless perception of happenings, Rosa refers to the distinction between two German terms that, as Walter Benjamin recognised, can be used to talk about episodes of present: Erlebnissen and Erfahrungen. Erlebnissen are episodes of mere experience. When we live through them, they seem never-ending and leave no trace in the memory. 
Because of this feature, Rosa calls them long-short experiences. Erfahrungen are instead experiences that leave a mark and contribute to building our identity. When we live through them, they seem to pass very quickly but leave a trace in the memory. Rosa calls them short-long experiences. A century ago, Benjamin complained with some concern that we were approaching an era rich in Erlebnissen and poor in Erfahrungen. Rosa stresses that today we are experiencing a world of short-short episodes (Rosa, 2010). In Erfahrungen, time seems to escape from both the sides: it goes fast and it does not leave traces in the memory. As a consequence, the episodes of present remain alien. We are not able to appropriate them and make them "ours", in the sense we are not able to turn them into events that are significant for us. This is the phenomenon that Rosa calls "alienation from time". Alienation is another central concept in Rosa's view and, following Marx, it indicates that state in which people pursue objectives and follow practices that no external agent or factor oblige them to do but they do not feel like doing or want to do (Rosa, 2010). Alienation from time, Rosa continues, is strictly interrelated with alienation from others and, as we saw, alienation from self. In fact, our identity and sense of self derive from our actions, experiences and relations, and from how we situate them and ourselves in the social and material world and in their space-time fabric.

Frenetic standstill, the sense of directionlessness, situational identity, alienation from time, and contraction of the present are all manifestations of the society of acceleration and of the future shock that acceleration produces.

Within education and, specifically, in science education, some attention has been paid to the implications of the society of acceleration on younger generations.

In fact, some researchers have investigated how the young grapple with an unpredictable future, a past that fails to provide clues to interpret the present, and a fragmented present that leads them to frenetically seize the moment, sniff out every opportunity, and keep open all possible scenarios. Since the 1990s, investigations have revealed worrying signs of identity fragmentation (Robinson \& Godbey, 1999; Sennett, 1998) and, more recently, the Eurobarometer survey has illustrated difficulties in young people in projecting themselves into the future (Eurobarometer, 2015). This result is consistent with other studies where students' writings on future have been analysed (e.g. Cuzzocrea \& Mandich, 2016; Heggli, Haukanes, \& Tjomsland, 2013; Heikkilä et al., 2017). These investigations have shown a duality in futures thinking: the young may see their personal future as positive and in their own hands, but view the national and especially the global future as hopeless, frightening and completely outside their influence (Cook, 2016; Heikkilä et al., 2017).

Papers and authoritative educational reports stress that these unprecedented levels of uncertainty and change necessitate the development of specific skills (e.g. Anderson, 2010; Rickards, Ison, Fünfgeld \& Wiseman, 2014). The recent position paper by the OECD (2018) is particularly explicit and focused on this. Anticipation, Action and Reflection (AAR) are the three main dimensions of the "compass" that, they argue, is needed to navigate the complexity and uncertainty of the current society. The future of education implies a responsibility to participate in the world and influence people, events and circumstances for the better. Agency and responsible actions are connected to futures-thinking: they emerge through reflective and anticipatory processes (OECD, 2018). Indeed, our hopes and thoughts about future opportunities influence our actions and agency in the present, "agency involves the idea of projection and implies anticipation" (Cuzzocrea \& Mandich, 2016).

All these issues strongly challenge science education for several reasons. Firstly, future views, being utopian or dystopian, are connected to science and technology (Carter \& Smith, 2003). Secondly, science education can play an important role in developing personal identity (Levin, 
Levrini \& Greeno, 2018) and, more and more explicitly, can become an explicit locus to promote "Erfahrungen" and guide students to appropriate time and develop the sense of self (Lavrini, Fantini, Pecori, Tasquier \& Levin, 2015; Levrini, Levin \& Fantini, 2018). Thirdly, many skills that are needed to navigate the society of acceleration and uncertainty can be easily related to scientific thinking and developed through the learning of science. We are referring, for example, to skills like scenario thinking, systemic thinking, thinking beyond the realm of possibilities, action competence, managing uncertainty and complexity, and creative thinking. Incorporating curricula activities in STEM that are aimed at developing such futures thinking skills would provide a deep contribution to aligning science education with societal needs (Branchetti, Cutler, Laherto, Levrini, Palmgren, Tasquier \& Wilson, 2018; Levrini, Tasquier, Branchetti \& Barelli, 2019; Tasquier, Branchetti \& Levrini, 2019).

\subsection{The present shock and the pandemic era}

We are all surprised by how the current COVID-19 pandemic quickly impacted many aspects of our lives and has deeply transformed the time structure that regulates our social and individual rhythms.

This situation shows aspects that are different from the society of acceleration as described by Rosa. First of all, acceleration has, today, a natural origin and, because of this, its pace of change is a matter of fact: nature is following its own evolution. All our cultural systems are following the virus diffusion and search to identify its biological, epidemiological and clinical features in order to slow down the pandemic contagion and save the health systems and societies. Available scientific, mathematical, and technological knowledge is applied and the production of new knowledge and technology is accelerated as far as possible. In this specific moment, science and technology is chasing behind the natural evolution of the virus in order to elaborate recommendations for governments, policy-makers and other institutional panels. Science and technology are fighting against time and many forms of uncertainty. For example, science is fighting against the lack of national and international standards for data collection and sharing, against the over-production of fake news or pseudo-scientific rumours that continue to influence people and, in many countries, against the slashing of resources in research and public health systems. Also, methods of interaction (in an official, reliable and trustful manner) with policymakers take time.

This race by science shows the dramatic dilemma for scientists, who have to balance the urgency of a situation requiring immediate responses with the time required by scientific methods, which is intrinsically longer (the time to collect reliable data, analyse them, elaborate models and hypotheses to test and revise, the time for peer reviewing and the time to move from foundational research to the production of drugs or vaccines).

Regarding policy-making, governments and municipalities are required to make immediate decisions in conditions of emergency to "flatten the curve" and try to limit the risk of collapse in the social and health systems. Even in the most virtuous cases, we are observing policy makers and governments who are reluctant to learn immediately from precedent experiences (for example, from China, South Korea and Italy). Part of the problem is that each government is focused to take into account also local political and cultural peculiarities, according to which decisions are based on different priorities or interests. When decisions have to be taken so quickly, the risk of asymmetric effects that favour some categories over others is very high. The search for an equilibrium between conflicting interests, objectives, subjects, institutions and their various 
dimensions (health, economic, psychological, societal, educational, ...) takes time but this time is also the ground of democratic systems and social cohesion.

In many countries all over the world, people are requested to lock down and stay isolated, and act as responsible citizens. From our houses, we are eyewitnesses to a worldwide phenomenon and, if we look carefully, dynamics and practices that are usually invisible can now be discovered. We can see and learn, for example, how science works, how our societies are organised, how our institutions and leaders work, what values (economy, health, public wellness, solidarity, or private interests) have been prioritised by our leaders. We can also learn about the role ascribed to science and technology in our social contexts and what role is designated to knowledge and education.

However, whilst we have the chance to observe these complex structures emerge, our daily time appears suspended. We are searching for new rituals, new habits, new priorities that can normalise and control the time of our daily practices.

Thus, time structure of this contingent moment is rather special. Outside, the public and social world is running as fast as possible to contain a disaster; inside, the private and daily world is grappling with a new form of slowness.

Sociology of time, mainly that which is influenced by feminist perspectives, has produced interesting reflections on these different dimensions of time: the time of daily life, the relationship between inner times and social time, and ethical responsibility as a connector between private and public realms (Adam, 1995; Leccardi, 2003).

The society of acceleration, Leccardi argues, has reduced the time of everyday life to trivial and repetitive rituals that have slowly disappeared from the attention of our societies. This time, instead, includes a precious embodied dimension where time is linked to concrete spaces and is made up of gestures, acts that follow multi-speed rhythms. In daily life time, the private and public world can be kept together (Leccardi, 2003) and, in the risky, fragile and global world, the future of our societies and the planet depends increasingly on everyday rituals (Beck, 2000).

One of the main impacts of the coronavirus period is the re-discovery of daily time and the recognition of its enormous value. This time is also a form of defence against the virus, as well as a way to become an agent in history.

Compared with the pre-crisis period, we do not feel a sense of alienation from time. On the contrary, we are all re-appropriating the meaning of our daily rituals and we are perceiving a strong sense of directionality: although the future is still completely invisible, we perceive that we are witnessing an epochal transition.

We call this general feeling "present shock" and we decided to carry out a survey aimed at investigating how the young are experiencing this present time and what role is played by science and its learning in this moment.

We are perfectly aware that this study is focused on, and carried out in, a very special moment. However, as many analysts repeat and as the climate crisis also shows, we are living in very fragile societies that are challenging the dynamics of the planet. Thus, we have to expect, in our futures, sudden and profound changes in time structures and paces. In this sense, future shock and present shock can be seen as intertwined - as different manifestations of the precarious equilibrium between nature, science \& technology, humans and societies. And science education has to contribute to equipping students with a compass to navigate this dynamic society.

As already mentioned, this study is a type of follow-up to the research we have carried out over the last fifteen years on appropriation and future scaffolding skills. These studies are widely described in other papers that we will quote. In the next section we sum up the main results that we used as background to design the study on present shock. 
Paper submitted to Science \& Education

\section{Background}

Firstly in an implicit manner, and then more and more explicitly, our research group in Physics Education has elaborated an approach that can contribute to answering three questions:

(i) can scientific knowledge offer the students skills and thinking tools to manage, both rationally and emotionally, the uncertainties about the future?

(ii) can scientific education offer students opportunities to live more serenely in the present of their experience?

(ii) can scientific knowledge foster the development of a dialogue with the past that takes on board the present context?

\subsection{Future-scaffolding skills}

Let us start with the first question: Can scientific knowledge offer the students skills and thinking tools to manage, both rationally and emotionally, the uncertainties about the future? This question has been recently investigated by the group within the Erasmus+ European project called I SEE Inclusive STEM Education to Enhance the capacity to aspire and imagine future careers (www.iseeproject.eu). During the three years of the project (2016-2019), the partners developed an approach to science education focused on empowering secondary level students to face the uncertainties of the future as individuals and as active citizens in society. The I SEE approach is described extensively in (Levrini, Tasquier, Barelli, Laherto, Palmgren, Branchetti \& Wilson, 2020; Levrini, Tasquier, Branchetti \& Barelli, 2019; Tasquier, Branchetti \& Levrini, 2019; Branchetti et al., 2018). During the project, four teaching-learning modules were designed and tested. Every module was built on a different "future-oriented scientific issue", i.e. a scientific, future-relevant topic that is also at the core of current societal debates and which may be of genuine interest to students. The modules, available on the project website, revolve around climate change, artificial intelligence, carbon sequestration and quantum computing. They were tested in Italy, Finland and Iceland and involved over 300 secondary school students.

Behind the modules' design lay two main assumptions. The first is that future is intrinsic to science (Levrini, Tasquier, Branchetti \& Barelli, 2019). Science education can be an extraordinary opportunity to educate on the future since it is an impressive source of knowledge for thinking and talking about the futures. In fact, the epistemic practice of building predictive models and causal structures for explaining and foreseeing natural or social phenomena is consitutive of science. Science has developed various models of causality. As well as the linear and deterministic models of Newtonian mechanics, 20th century science has elaborated more and more sophisticated probabilistic models (Tasquier, Levrini \& Dillon, 2016). Quantum physics and the science of complex systems are extremely rich sources of concepts such as space of possibilities, future scenarios, projection instead of prediction, uncertainty, feedback and circular causality, which can be suitable for development into skills for thinking and talking about the future (Levrini, Tasquier, Branchetti \& Barelli, 2019) as well as for developing citizenship skills (Barelli, Branchetti, Tasquier, Albertazzi \& Levrini, 2018). This assumption led us to design teaching activities aimed at making the scientific temporal patterns and causal models explicit. In particular, we designed activities on complex systems to enable students to become acquainted with the language and tools (e.g. simulations) of the science of complex systems and its societal implications, so as to turn 
scientific knowledge into skills for talking and thinking about the futures (and, hence, about the present and past).

The second assumption is related to the fact that we are experiencing a period of future shock. As a result skills needed to grapple with the future have been included in the lists of transversal or soft skills strongly requested by STEM-based industry leaders (e.g. SHRM 2019; WGSI, 2018) and economic organisations (OECD, 2018). This second assumption led us to design activities aimed at developing skills for anticipation and reflection, for imagining possible and desirable futures and becoming agents - taking action - in the present (OECD, 2018).

The analysis of the data collected during the various implementations of the modules allowed us to detail students' reactions to the modules. This process led progressively to refinement and characterisation of the ways in which scientific knowledge can provide tools to manage the complicated relationship of youngsters with the future. In particular, we found operational markers i) to describe the change in the perception of the future that the students experience through the modules and ii) to identify future-scaffolding skills, i.e. skills that help the students to construct visions of the future and to imagine ways to act in the present with an eye on the horizon (Levrini, Tasquier, Branchetti \& Barelli, 2019; Tasquier, Branchetti \& Levrini, 2019; Levrini et al., 2020). The change in perception of the future was articulated in two phenomena: widening and approaching. Through the modules, the students experienced a widening of possible ways of thinking, roles of stakeholders, and actions to address the future-oriented scientific issue tackled in the module. Moreover, they ended up perceiving the future as approaching themselves. From far and unimaginable, the future became closer to students' imagination, to their present reality and to their personal, social and professional growth path.

Regarding future-scaffolding skills, we identified two macro-categories: structural and dynamical skills. The first are abilities to organise pieces of disciplinary knowledge and build systemic views through an intentional and conscious process of scaffolding. With structural skills, particular attention is given to the recognition of causal, temporal and logical relationships within the futureoriented scientific issue and its multiple dimensions. The rational scaffolding provided by the structural skills set the basis for the other category of skills, dynamical skills. These represent the ability to navigate across the scaffolding and complexity of knowledge, without trivialising the relations between local details and global views, the relations between past-present-future, and the role of individual and collective actions. They also consist in thinking creatively to imagine new possibilities and concrete actions, balancing the need to aspire with that of keeping one's feet on the ground, thinking in terms of multiple possibilities rather than in terms of necessity.

These studies on future led us to ask how the young generation is experiencing this period of pandemic and isolation. Within I SEE we touched upon the great difficulties encountered by young people in imagining their futures and we closely experienced how challenging and demanding it was to guide them to develop future-scaffolding skills. As a result, we felt a strong need to create a new baseline for our investigations and to define a framework that reflects on the role of science education in supporting the young as they navigate through fast-changing space and time structures. This is the main reason that pushed us, during our quarantine period, to design and complete the study that we will present in Section 4.

\subsection{Appropriation and its contribution to reflecting on how science can contribute to developing skills for managing present and past}


Let us now move on to the last two questions that directed the research we have been carrying out for the last 15 years: (ii) can scientific education offer students opportunities to live more serenely in the present of their experience? (iii) can scientific knowledge foster the development of a dialogue with the past that has taken on the present?

Taking into account a number of possible ways to tackle these questions, our approach is characterised by a focus on the forms and epistemic structures of knowledge organisation (Levrini, Levin \& Fantini, 2020). Specifically, it aims to provide empirical and theoretical results on which, how and why some forms and structures of knowledge organisation can enhance, in class, the creation of "moments of Erfahrungen", by boosting processes of personal sense-making and by nurturing idiosyncratic tastes, talents, skills and aesthetical preferences (Kapon, 2017; Levrini, Levin \& Fantini, 2018).

All the materials we have designed so far (on special relativity, quantum physic, thermodynamics, artificial intelligence, quantum computers, and climate change) share three structural features that we call multi-perspectiveness, multi-dimensionality and longitudinality (Levrini \& Fantini, 2013; Levrini, Levin \& Fantini, 2020).

Multi-perspectiveness means that the contents are organised to show that, even in science, there can be a polyphony - the presence of different voices that confront, dialogue and concert. In order to implement multiperspectiveness, our materials have been designed to show that the same disciplinary contents can be analysed and interpreted from different perspectives and according to different approaches (for example, the macroscopic and microscopic approaches in thermodynamics, or the algebraic-operationist and geometric approach in special relativity). The main message we want to transmit is that, even in science and its history, different authors/physicists, while respecting the same constraints (the same objective core of knowledge), can support different interpretative theses.

To emphasise this point, the materials are selected, shaped and organised to flesh out a multidimensional architecture through which the contents, and different perspectives, can be analysed. Specifically, multi-dimensionality means that the different perspectives are compared across multiple levels: conceptual, experimental, and applied but also, and mainly, for their philosophicalepistemological peculiarities (Levrini, Levin \& Fantini, 2020). Multi-dimensionality is introduced operationally through a plurality of activities, including the analysis of historical-epistemological essays. For example, in special relativity, the algebraic-operationist approach and the geometric viewpoint are analysed by comparing not only the formal tools that sustain the two perspectives, but also the epistemological approaches to space and time that Einstein, Minkowski and Poncaré implemented in their original papers (Levrini, 2002; Levrini, 2014). A special emphasis in the materials has been awarded to the distinction between substantivalism and relationalism, which has always characterised the debate on space and time in physics and in philosophy. According to a substantivalist perspective, space and time are empty containers whose existence are independent of the existence of matter and phenomena. The Newtonian view of absolute space and time is the most important and best-known case of substantivalism in physics, but also Minkowski follows this line and current string theory is based on a given spacetime background (Greene, 2004). On the other hand, relationalists retain that space and time are nothing but relations that individuals or societies invent to organise, measure or understand phenomena. The notion of empty space and empty time do not make any sense for a relationalist, due to space and time existing only as relations or conventions. Leibniz, Mach, Einstein, and Poincaré, as well as loop theory adherents, are supporters of this view (Smolin, 1997). 
As these examples show, in some of the modules we designed, we have already addressed issues that are very relevant to the topic of this paper, even though the original goal was not to shed light on the structure of time.

The third feature refers to longitudinality. Materials are built also on cross-cutting themes like modelling, data-analysis, testing, and forms of reasoning and argumentation. Through these themes, students are encouraged to move beyond the various theories and topics they are learning and to recognise common epistemic patterns that characterise science and physics, in particular. In Bologna we have been experimenting for over 15 years with these materials in classes of secondary school students (17-19 year old students) and we have observed the systematic manifestation of similar results:

(i) the approach favours processes of a deep understanding of content, and favours processes of conceptual change (Levrini \& diSessa, 2008);

(ii) triggers interesting inclusion dynamics, making the learning environment "psychologically safe" (many more students, even those who we would not call "talented and skilled in the scientific disciplines" have found access to scientific discourse and have been able to "position themselves" in science and in the classroom) (Levrini \& Fantini, 2013);

(iii) favours an appropriation process, as intended by Bakhtin (Levrini et al., 2015).

It [a word] becomes 'one's own' only when the speaker populates it with his own intentions, his own accent, when he appropriates the word, adapting it to his own semantic and expressive intention. Prior to this moment of appropriation, the word does not exist in a neutral and impersonal language (it is not, after all, out of a dictionary that the speaker gets his words!), but rather it exists in other people's mouths, in other people's contexts, serving other people's intentions: it is from there that one must take the word, and make it one's own. (Bakhtin, 1981, pp.293-4).

Regarding the last point, we observed a very interesting phenomenon emerge in class. During and after class work, the language used by the students progressively changed. "Schoolish" language, which is often heard in our classes when students borrow words from the teacher or textbook, was no longer spoken. The words of science had become "theirs". The students projected onto this lexis their intentions, tastes and inflections. They began to speak an "authentic" language, which had meaning and relevance for themselves as well as being respectful of consolidated knowledge.

For example, at the end of the thermodynamics unit, there were class discussions and individual interviews. When we talked about temperature and asked students what temperature was, they did not repeat the definition of the text but gave personal answers like the following.

For Michele, temperature was that quantity whose gradient is what makes engines work. Michele was a student who, through the learning process, found his own way to understand the applications of thermodynamics on machines.

For Matteo, a student who did not particularly like physics and especially its formal and application dimension, temperature was understood as that quantity that compares both in the state equation of perfect gases $(\mathrm{PV}=\mathrm{nRT})$, and in the law of calorimetry $(\mathrm{Q}=\mathrm{cm} \Delta \mathrm{T})$. Temperature emerges, therefore, both as a state variable (the state equation describes an equilibrium state) and a quantity whose gradient triggers a process, a change (the process of exchanging energy in heat mode). This double role was, for him, the most important point of the whole path, together with the concept of entropy and arrow of time, because there he had found a point wherein to project, as Bakhtin would 
say, the thing that seemed most dear to him: the philosophical difference between being (a state) and becoming (process and change).

As extensively reported in the 2015 paper, other students, like Michele and Matteo, found their own ways to sense-making (Levrini et al., 2015).

Thanks to the richness and articulation of student discourses, it was possible not only to claim that students appropriate scientific words, but also to point out an operational definition of appropriation. This definition was built on five markers that, when applied to students' discourse, allowed us to recognise whether students' terms/utterances did in fact reveal appropriation. The discourse of students who spoke their own language presented the following features, being:

A. developed around a set of words or expressions repeated several times and linked together so as to express a personal, idiosyncratic "signature" idea with respect to a physics topic (thermodynamics in that case);

B. disciplinarily-grounded i.e. the signature idea was used by the student to understand scientific concepts in the sense that it was used as a tool for focusing on pieces of disciplinary knowledge, selecting and re-assembling them to make sense of the specific concept (e.g. temperature);

C. thick i.e. the signature idea involved both a metacognitive dimension (showing what learning physics means for the student) and an epistemological one (showing what sense of the discipline the student has);

D. non-incidental, i.e. the signature idea was expressed in several activities throughout the students' classroom experience, not just in one interaction or in the moment of the interview;

E. carrier of social relationships, i.e. the signature idea allowed the student to play a specific role in class discussions, and this role was acknowledged by others in the classroom community.

The markers indicate that appropriation is a multi-layered process where the students take an idea and elaborate it according to their own interests and testes (marker A), coherently use the idea to position themselves with respect to disciplinary knowledge (marker B), with respect to others (marker E) and with respect to their own personal story of who they are as a person and a learner (markers C, D).

This phenomenon was favoured by the polyphony and multidimensionality created in the classroom by the materials. This articulated structure encouraged authentic processes of identifying and positioning with respect to the discipline, personal tastes and others (Kapon, Laherto \& Levrini, 2018; Levrini, Levin \& Fantini, 2018). The materials also allowed the teacher to enact specific orchestration strategies that resulted very effective in supporting and legitimising such dynamics (Levrini, Levin, Fantini \& Tasquier, 2019).

As a result, also the study of a topic like thermodynamics became a context where the students could slow down the time of their experience, dialogue with voices of authoritative thinkers from the past, play with their own ideas and search for strategies of sense-making. This is why we think that our approach, aimed at fostering appropriation, is one possible way to answer the first two questions that opened this section, and show how scientific education can offer students opportunities to live more serenely in the present of their experience and effectively dialogue with the past. 
In the next section we will show how the markers of appropriation inspired a way to investigate how teenagers are now grappling with the present shock and whether they are searching for strategies to appropriate their time in the pandemic era. The survey will show that the markers are helpful for outlining articulated profiles of time management but, unfortunately, the markers will also reveal that science, as usually taught in schools, provides very few, if any, tools to interpret and understand what is happening. This result will underline the need to revise curricula and include, evermore explicitly, epistemological, political and societal dimensions.

\section{The survey}

\subsection{Goals, target and methods of data collection and data analysis:}

The study was carried out to answer the following questions:

a) How are secondary students experiencing time and what, if any, knowledge are they using to grapple with the changes in its pace?

b) How can science and STEM curricula and materials be revised in order to prepare future generations to deal with global concerns such as pandemics and climate emergency and, in particular, to grapple with quick changes in the time structures of our complex and fragile risk society?

The survey was designed with an exploratory and piloting nature. It was not meant to provide comprehensive answers but to pave the way and lay the foundations for further, wider and more focused, rounds of investigation.

For this exploratory survey, we chose the tool of extensive individual interviews and a qualitative approach for the analysis. We then decided to focus on a special group of secondary school students. We selected students at the end of their secondary studies (17-19 years old, grade 12-13), close to making their own university choices and particularly interested in science (a scientific degree course was seen as one possible option for their future university career). The students that we involved in the survey had attended extra-curricular courses on advanced STEM topics (quantum computers and climate changes), organised by our Department, in January and February 2020. We chose these students to maximise the probability of encountering teenagers who refer to or use scientific knowledge and competences to deal with the current changes. In this sense, we considered them particularly suited for 'breaking the ice', hewing the theme and providing tips to refine tools and aims for further stages of the research. Indeed we do not only aim to describe the present shock, but also to draw some conclusions about the contribution that an appropriate approach to science education can give to managing it, emotionally and rationally.

Nine students ( 4 female and 5 male) agreed to be interviewed. They were all attending the same type of school, a "Liceo Scientifico", scientific-oriented secondary schools in Italy. But they did not know each other, since they were from different schools which were also in some cases in different cities.

The protocol of the interview is reported in the Annex. It includes 23 questions, articulated in two main sections:

Section 1 - questions about the organisation of their daily life and the ways they were experiencing the lockdown and social debates on the pandemic;

Section 2 - questions about their perception of time. 
In the first section, the questions concern the changes they perceive in their everyday life, the role they ascribe to school and school science, the role of science they see in the current social and political debates, the channels of information they use, the kind of individuals they consider experts and the type of trust they feel.

In the second section, the questions regard: a) the role played by past, present and future in their thinking when they have to deal with difficulties and/or to make personal choices; b) their perception of time in the present daily life; c) their perception of the future in the short, medium and long-term period, b) their perception of the scale of the pandemic in the "big" history and its effects on social transformations.

We used three main criteria for the specific formulation of the questions:

- the questions had to reveal, where existing, future-scaffolding skills;

- the questions had to foster a relaxing interaction aimed at development of thinking and generating knowledge in the interaction;

- the questions had to make the interview a significant moment, during which the students were guided to elaborate their own experience,discover possible ways to grapple with its novelty and participate in the social debates.

The protocol reported in the Annex is the result of a process of refinement. The first three interviews served as trials to simplify and clean up the formulation of the questions and to reduce unnecessary repetition. The interviews were conducted in video-conference by OL, SS and GT. Each of them lasted between one hour and 75'. They were produced during the lockdown period in Italy, from late March to early April, 2020. The interviews were audio-recorded and transcribed. The data was analysed through methods inspired by grounded theory (Anfara et al., 2002; Glaser \& Strauss, 1967), which we generally apply in the analysis of extensive interviews (Levrini et al., 2015; Levrini, Levin, Fantini \& Tasquier, 2019). The analysis was performed through explicit back and forth dynamics, from data to their theory-oriented interpretation. In accordance with our second research question, the interpretation is also oriented toward concrete support for teaching. To reach this aim, we carefully developed data analysis with a special eye on its usefulness in providing concrete recommendations for the design of teaching activities in science education.

This combination of bottom-up and top-down processes, from data to theoretical interpretation and vice versa, was carried out through a series of systematic de-briefing and triangulation meetings among all the authors of this paper. The overall process comprised four phases.

\section{Phase 1 - Data overview and search for the sensitizing concept (Glaser \& Strauss, 1967)}

The first phase corresponds to an overview of the whole corpus of data so as to identify a sensitising idea that could guide us in data immersion. The compass we initially used to navigate the corpus was inspired by the notion of "future shock". We examined the data by identifying which pictures of the future emerged and looking for analogies between the future-scaffolding skills and the skills that the students declared or revealed for managing such a period of emergency. The idea was to search both for similarities and differences as compared with findings in previous studies. We expected that the pandemic would produce some change in students' view of the future and, in some sense, we expected that such a quick change could have inspired them to question their personal, professional or social scenarios. At the beginning, this phase was very frustrating since the answers to the questions on the future were the poorest part of the interview and the way students talked about their strategies and feelings in this period were very weakly linked to the categories we had elaborated and refined in our previous experiences. They either mirrored a 
general tendency to deny thinking about the future ("I do not see any differences in my way of perceiving the future", "I remained pretty much myself") or reproduced the well-known distinction between a concrete and positive image of a personal future and an uncertain one. Sentences like "this pandemic will finish and I will go back to my normal life", "my plans have not changed, I am just thinking about ways to get through this period as well as possible" or "I'm looking forward to starting university and gettng on with my life" were very frequent.

It soon appeared clear that the pandemic did not act significantly at that level and that the future was not the most interesting theme or time dimension of the interviews. Although we found this result initially surprising, we then realized that it was coherent with the sociology of time and with our hypothesis that the pandemic acts more on perception of the present. In particular, the most satisfying moment of the first phase was the discovery that, maybe, students were grappling with the issue of appropriating or re-appropriating their own present time. Starting from this intuition, we fleshed out, as a sensitising idea, the hypothesis that our appropriation markers could be revised and used to capture how students were grappling with time and, in particular, how they were trying to stay consciously in the present of their current experiences. This intuition moved us forward to the second stage of the analysis.

\section{Phase 2 - Construction of a shared grid for data analyses}

The second phase corresponds to the elaboration of the analytical grid. We started from our appropriation markers and revised them so as to fit with the theme of the interviews. The change of context, from appropriating a physical concept to appropriating time, naturally required a significant adaptation of the five markers which were then transformed into the following sets of questions, used in the interview:

a) Is there an idiosyncratic idea about time management which the students focused on in the interview (what terms, expressions...)?

b) Does the student use disciplinary/school knowledge (particularly scientific knowledge) to manage their time (grounded in the disciplines)?

c) Is the core idea thick, i.e. is the student able to develop her/his core idea in a consistent way throughout the interview? Does she/he appear aware of it?

d) Is the idea non-accidental, i.e. does the interview suggest that the core idea is grounded on experiences and reflections that are not only suggested by the contingency of the interview?

e) Is the idea a carrier of social relations and/or does it allow the student to see her/himself situated in society?

Two further set of questions have been formulated with the explicit aim of reminding us to remain focused on the theoretical orientation of the analysis and the relevance of the results for teaching:

a) What contribution does the interview make to help refine the idea of present shock and to build a baseline framework on students' strategies to managing fast-changing space and time structures? Do a sense of slowness, directionality, and the importance of daily rituals emerge? Do they see their role in social cohesion and as agents of history?

b) What contribution does the interview make to help us build an argument about the role of science education and the role of disciplinary knowledge to equip the students with knowledge and competences to manage fast-changing space and time structures?

The questions have been slightly reformulated throughout the process of analysis to make them significant for all the interviews and effective in capturing the most interesting points of the students' discourse. 


\section{Phase 3 - Immersion in the data and profile construction}

The third phase was the core of the analysis, represented by full immersion in the data. The application of the analytical grid allowed us to outline students' profiles. Only six complete profiles were produced, on the basis of the interviews carried out with the same revised protocol. The first three interviews that we used to test the protocol have been considered as sources to comment and discuss the results.

Before applying the grid to the whole corpus, we started with two interviews to check whether the questions made sense and were easy to apply. To make this check, at least two people, independently of one another, listened to the interviews and highlighted the most interesting excerpts directly on the transcripts (pure bottom-up process). Then, two or three researchers compared the highlighted sections and, having agreed on the selection, the sentences were compared with the questions and positioned under the question they were judged to best answer. We quickly realised that the set of questions was effective in capturing all the highlights and for organising them in an apparently faithful profile of the student. At least two researchers worked on each "profile". When all the profiles had been drafted, we realised that the initial formulation of the questions left room for different interpretations and this compromised the comparability of the profiles. We then organised an alignment meeting to share an increasingly operational elaboration of the questions.

The meeting resulted in the following list of instructions:

a) to search for the idiosyncratic idea, check if there are words that the student repeats more frequently to talk about her/his way to manage time, which cannot be ascribed to the interviewer. If so, select the core sentences where the key-words are structural and try to paraphrase the core idea with a catchy sentence that can help transmit the essence of the idea. As a final step, select from the interview all the excerpts that show if and how the idea has been elaborated throughout the interview.

b) In order to check whether the core idea is related to disciplinary/school knowledge (in particular scientific knowledge), focus on all the parts of the interviews where the students talk about subject matters or science. Distinguish between the sentences where she/he mentions contents, the sentences where epistemological or methodological aspects are used or mentioned and, finally, sentences that refer to the theme of science $\&$ society and/or to the role of experts.

c) In order to check the thickness of the concept, search for its consistency within the interview and, where possible, its nuances and articulation throughout the interview. We are making the hypothesis that inner consistency of the discourse can reveal a form of awareness and depth of thinking.

d) Consider that accidentality refers to the fact that students' discourse does not touch upon identity aspects but has arisen spontaneously under the stimulus of the interview questions. Thus, in order to check and "measure" non-accidentality, check if the student mentions or refers to experiences and thoughts from outside of the interviews. Be careful to tremember that we are all experiencing an extraordinary period. Thus, distinguish, in the interview, between two types of accidentality/contingency that the student can show: the accidentality of the interview (is she/he inventing a position just to manage an issue, contingently raised by the interview?); the contingency of the pandemic (is she/he reporting about an issue that she/he had never addressed before, because of the novelty of the COVID-19 crisis?) 
e) In order to check if the core idea plays any role to position the student in society, describe the social network mentioned by the student (if she/he refers to friends, family or society more on general) and describe the eventual links between the core idea and the type of interpersonal relations and social positions in which she/he feels immersed now or in the future.

On the basis of this operational grid, we finalised the extended profiles, which can be downloaded here.

\section{Phase 4 - Double check of the profiles and results}

Once we had all the profiles, we compared them first with each other and then against our theoretical framework. The comparison was carried out along three axes:

i) the pictures of time that emerged from the interviews; ii) appropriation and its contribution to defining present shock; iii) the role attached by the students to science and its learning.

Regarding the first point, we operationally focused mainly on the first part of the profiles (the core idea that emerged by applying marker a) and, after a summary of the various views, we tried to extract an overall picture. As for the contribution of our appropriation analysis to the construct of present shock, we operationally referred to a summary on the five markers application, as well as to the first extra-question, which concerned specifically the contribution of the appropriation analysis to the sense of present.

Finally, in order to compare the roles that science knowledge and education played in students' approach to managing the crisis, we operationally focused mainly on the second part of the profiles (the results of the application of marker b), as well as on the last extra-question. From there, we identified indicators for the next agenda for science education.

The results from this phase are presented and discussed in the following sections.

\section{Results}

\subsection{How young students perceive time in the pandemic era}

The first result concerns the emergence of an articulated and stratified picture of students' perceptions of time. From the profiles, three main conceptions of time can be recognised: i) time as an opportunity to immerse yourself in experiences (4 students); ii) time as agenda (1 student); iii) time as an empty container to fill (1 student).

We use this macro-structure to present the students and sum up the core idea that they expressed in their interviews.

In order to protect anonymity, students are identified by pseudonyms, but gender distinction is maintained.

Returned time as an opportunity to immerse yourself in experiences (Chiara, Alessandro, Gabriele, Laura)

Four of the six students in question see the current time as an opportunity to immerse themselves in their experiences.

Let us start with Chiara. The core idea of time that emerged from her interview is: 
"In the motionless and suspended time created by the pandemic, one can find ways to manage the oppression of the present with new activities to control time and by escaping with the imagination toward fantasy scenarios".

All of Chiara's interview revolves around her perception of "velocity" of time. Before the coronavirus crisis, she was "really full of things to do, time passed very fast". Now the time has slowed down and "it is much slower, actually, it is also more difficult to face [...]" she feels that "time is a little suspended" she "never really feels it moving". The stillness of the present is coupled with a sense of anxiety caused by everyone around her talking about the pandemic: "Ifeel very surrounded by all this. The news every day, my mom, my dad, my friends who talk about it". This perception of time regards her experience of the present. Indeed, she recognises differences between her time and the time of society from which she feels detached: "they all move super-fast, actually, they all seem much more on it [...] everything outside happens very fast".

Chiara has found two main ways to manage the motionless and oppressive present. Firstly, she enriches her daily routine with a lot of new activities (cooking, playing the piano, training, videocalling friends). From the interview, it is clear that these activities are not only new rhythms with which she fills the empty container of her time, but new distractions to control time. The other way she has found to manage the oppression of the contingency is mental escape, which makes the present lighter and more livable. She often loses herself in a fictional world in which she is not surrounded by reality, and this is not only something she likes but something that really helps her: "Also watching movies... in this moment it's nice to see the dystopian ones or science fiction [...] it helped me a lot to have read, to have seen some apocalyptic films".

As well as Chiara, Alessandro expressed in his interview the idea that the pandemic has allowed him to recover time which, free from external commitments, is a "time given back". For Alessandro, this time is a great opportunity to immerse himself in personal intellectual experiences. Moreover, it is also a good opportunity to look for new ideas for reflection on social issues with two goals: to acquire new knowledge, but also, and mainly, to broaden his own "points of view". Alessandro is deeply aware that building thinking tools is not an immediate and easy process. It takes time.

The organisation of the day must certainly take into account school commitments, relaxing activities, social conversations with friends, but above all there is room for "that free time", which is no longer a "counted time". There is the possibility to choose how to use these "slices" of one's time, and for Alessandro it means having the possibility to immerse himself in personal intellectual experiences: latent intellectual interests, such as an interest in philosophical thought, could reemerge and be developed. The "returned" time is therefore not the counted time of the clock, but a mental time, the time necessary to cultivate "that thought" - free from other thoughts - .

"It re-emerged in this period [the interest in philosophical thought], I already had it, I just didn't have "slices" of free time, and [...] now it's coming out quite disruptively, [...] I'm glad because there are all the conditions necessary to bring out the interest. [...] Now I can "slice" me up some time and dedicate myself only to that and I like it even more because I can immerse myself in it ...".

"Returned/liberated time" is that time "to stop and rethink oneself" both as regards the personal dimension linked to one's own interests, dreams and expectations for the future, but also as regards the social and political sphere.

The third student, Gabriele, also took this moment as an opportunity to immerse himself in his thoughts. In the interview, he expresses the idea that the "right way" to spend his restored time is looking for the essence and the truth of what is happening, looking at history as a source of 
knowledge about "mankind", the "invariant", "what does not change", in order to pursue progress and improve the human condition. He refers to two kinds of time: internal (personal) time, to be filled in the right way ("you have to find the right way to occupy time") with passions, reflections and trying to find the "right non-routine routine", and external time, the "time of mankind", which is linear, deterministic, concerning "what lasts", "what does not change" ("... man is always the same, man always does the same things ... technology changes, changes ... there is incredible progress but in the end it is always man, it is always him ...").

From what he perceives as a privileged position, Gabriele observes that this pandemic period tears/removes the veil of Maya, obliging people to become aware of all the critical issues and difficulties that have always existed:

"the virus simply showed [the problems we are observing on a social level], but we were already in a relative moment of crisis ... [...] But it has always been like that ... that is, there have always been... simply that before they were directed toward different topics, [...] the virus brought nothing new except this state of quarantine".

It does not create any sense of upset in Gabriele, since he experiences the crisis as something "outside of him" ("really the concept of quarantine itself, of this ... of this virus ... I don't feel it ... it's not inside me ..."). The right way to spend time is, therefore, exploring the surrounding world by searching for the essential, by finding invariants that are not scratched by time.

Then we have Laura. Like Alessandro, Laura describes time as a personal non-routine construction, which has to be invented and re-invented by fitting together as many activities as possible: "the better I can fit things together, the better I can manage them."

The pandemic caused a "drastic change" in her daily life organisation: from rhythmic days organised around extra-school and outside-home commitments, to the problem of finding other activities to fill the time.

The quick change imposed by the pandemic led her to lose, at the beginning, any sense and conception of time: "I'm mostly losing the concept of time, completely ... that is, not what day it is today ... for example, I don't have the perception of when it was a week ago ..."

After an initial moment of great bewilderment, the awareness that it was necessary to react emerged. At first it seemed like resignation, then she found a way to rearrange her time by allowing old passions to re-emerge, like playing music, reading novels, and mastery of astronomical topics. The implications of the drastic change that she complains most about regards the fact that many out-of-school commitments, like a course on particle physics at CERN planned for the immediate future, have been cancelled. They represented "certain moments", sort of milestones, in her path toward the choice of university. The solution she found to replace these activities is to read and study the syllabus of university curricula and try to imagine herself, in the future, attending those courses: I think yes, it gave me confidence and certainly comfort to see what I could do, I have to say that looking at the degree courses or things like that is making me excited, so ...

All these aspects show that time, for Laura, is neither something awarded by external or social constraints, nor an empty container to fill, but a personal construction built by fitting and cultivating personal interests and passions.

Time as agenda (Giorgia)

One student, Giorgia, describes her way of grappling with time, which is rather different from the students we have discussed so far. Giorgia's interview revolves around the following core idea on 
time: "I have to try to understand how to manage time better and try to take advantage of this time that now I have".

Time, for Giorgia, emerges as a personal agenda that she creates in accordance with external commitments so as to optimise her personal path and pursue her goals. Lockdown is seen as an opportunity to have empty slots that have to be capitalised upon.

She feels as though she is in a crucial moment of her life where she has to choose the university degree course and she feels the pressure of this choice: "especially in this period I have to think about my university choice and it's not easy because, anyway, maybe I choose the wrong option; that is, it seems that if I make this [wrong] choice, this will be my future.";

Giorgia is very focused on adhering to her daily routines, whilst she does not follow any political, sanitary, or public debate. School and homework, Instagram, Youtube and apps to chat with friends help her to routinize very concrete activities (including, for example, learning to edit videos). Youtubers and influencers also help her to "accept also empty times": "[There is] a woman, a Youtuber, who has [been] a kind of comfort because [...] She said that it is normal that in this situation there are moments when, in fact, you would not feel like doing anything."

The core idea appears strictly related to her self-confidence and trust that, if she focuses on her training and if she works hard, she will be able to reach her goal to achieve a leadership position: "I always imagined myself, I don't know in what area, I don't know how, I don't know where, but that $\underline{I}$ was able to reach a high level in what I was doing. [...] I have always seen myself, since I was a child, perhaps very probably also very influenced by the films I saw and various things, just "I who enter my office as a boss, manager of what I'm doing". So my job, my great goal is to be able to reach that level..."

A similar position is expressed by Caterina and Dario, two of the three students we interviewed without outlining the profiles. Caterina and Dario are also very focused on their education and, in addition to capitalising on the extra-slots to improve their calculus skills in order to become researchers in physics, they are also taking the opportunity to learn to strengthen their "resilience" (Caterina) or concentration (Dario) skills.

\section{Time as container (Stefano)}

Only one student, Stefano, expressed the implicit idea that time is a container that has to be managed by filling it with engaging and enjoyable activities. Daily time is perceived as an ordered, rhythmic organisation of school commitments and social activities with friends. Stefano is particularly interested in scientific subjects (physics and mathematics) and his identity is strongly related to his being a very good student, extremely talented in physics.

Because of this time perception, the COVID-19 crisis did not create a deep sense of disturbance: his world and his temporal organization are still, as before the crisis, populated by rites of daily life that involve (above all) his school commitments, the study of physics and video-chatting with friends - this activity is aimed both at sharing leisure time and helping each other in scientific disciplines and any technological issues related to distance learning.

The main change in his time management produced by the COVID-19 crisis concerns a sense of emptiness and a sense of urgency. In particular, regarding the sense of urgency, he stresses that the crisis showed that time should not be wasted and priorities can be changed:

The priority of things has changed; if before I did $A, B$ and $C$ now I have realized that $C$ is more important and therefore I dedicate more time and, above all, more energy. Before I would say 'okay, I'll do it tomorrow' - now it's not tomorrow, I have to do it now. 
The rituals and hobbies allow him to feel protected from the external world and external suffering. He does not follow any social debate since he finds them painful and he and his friends prefer to take the situation more lightly:

We take the situation as a game, but not a game intended as fun; also because according to Instagram there are many jokes, a lot of jokes about this situation that is happening, probably I also didn't really understand what it is and therefore we don't feel this great need to say "oh my God, this is happening", [...] so we don't feel this great need to remember it even when we are together [with friends], when we are together it should be a moment of relaxation ...

\section{Comparison of profiles}

The three-pronged picture of time perceptions that emerged from the profile (time as container, time as agenda, time as personal time of immersion in the experiences) mirrors the debate between substantivalism and relationalism that can be traced back in the history and philosophy of physics. The distinction of space-time as containers or as relations, indeed, seems to capture the two more general ways that people use to think of and to talk about time. In students' conceptions, we can recognise, in the words of Stefano, the echo of the Newtonian conception of time as an objective container that "Absolute, true and mathematical time, of itself, and from its own nature flows equably without regard to anything external, and by another name is called duration" (Newton, 1687). All the other students appear to be agents of their time and their words echo the view of space and time as a set of relations: a social or personal construction, elaborated to organise experiences and provide them with "an order of succession" (Leibniz, 1715-16 in Alexander, 1956, Third Paper, paragraph 4; G VII.363/Alexander 25-26). From our bottom-up analysis we found two different ways to conceive the relations that create the sense of time: "an order of succession" to be ascribed to activities and organise daily time according to that agenda; a time generated by immersive experiences in personal thoughts. The first is the case of Giorgia, whose time is created by planning her activities so as to capitalise on experiences and select the most relevant for her future. For the other four students (Chiara, Alessandro, Gabriele and Laura), the sense of time is created by immersion into personal reflections that can involve different plans: imaginative (Chiara), socio-political (Alessandro and Gabriele), intellectual (Alessandro and Laura).

This last remark highlights the fact that the overall picture emerging from students' profiles is definitively more nuanced than the three-pronged macro-structure we fleshed out through the philosophical-physical lens. Such richness needs a different lens in order to be captured.

As we stressed in our theoretical framework, time is used in sociology as a perspective to build a map of social transformations and find a code to interpret them (Leccardi, 2009). Also identity, a complex construct situated in the nexus between the individual and the collective dimensions, can be shaped in terms of time structures. Identity incorporates the irreducible tension between idiosyncratic and distinctive traits - the need to feel different from all the others (the Latin sense of "ipse") - and social and inter-subjective aspects - the need to be recognised as part of a community and belong to a group (the Latin sense of "idem"). diSessa distinguishes between intrinsic identity and managed identity (diSessa, 2018). The first "concerns patterns inherent in our varied and distinctive ways of interacting with the world, including the social world." The second refers to actions we all "take to present ourselves to others in felicitous ways (including, but not limited to, "as we see ourselves")" (diSessa, 2018). Within moments of deep change, the identity tension includes dealing with the need to realign our self-perception as agent or receptors 
of change, producers of sense-making, as well as the need to refine our norms and criteria to manage ourselves with respect to others. All these identity practices have a time structure, since they are, more or less implicitly, regulated by rituals and routines that shape our "reflective project" made up of selective processes, exploration of options, decision-making processes.

If we observe students' interviews and analyse the time structures with the lens of "identity" and of the relationship between individual and social dimension, we discover an impressive richness.

First of all, we can see that all the students try to organise their time management to maintain an unchanged sense of self (their intrinsic identity). Stefano, Giorgia and Gabriele were very keen on sustaining that the crisis did not really change their intrinsic identity: this emerged in their way of considering lockdown as an opportunity to strengthen those routines or thoughts that they feel most "essential" (learning physics, training, observing "mankind"), and to legitimise them even further, for example by awarding these rituals more time and more centrality in their daily life. Chiara, Alessandro and Laura perceived the change in a more significant way and had to change their rituals to preserve their inner sense of the self. Chiara had to invent new ways to control time and the new sense of oppression that she felt. Alessandro took the opportunity to widen his views and discover new perspectives from which society could be observed. Finally Laura had to change profoundly the activities that generate her sense of time and, mainly, her sense of self.

A second aspect that the sociological lens allows us to recognise in students' profiles regards the time structures used to describe either their personal or social dimensions. This focus illuminates interesting similarities among the students but also strong differences.

In general, it seems that all the students perceive a significant misalignment between personal time and social time. This is very evident in Chiara and Gabriele. Chiara feels the oppression of the difference between the stillness of "suspended time" of her present and the speed of society that "moves super fast". Gabriele recognises a different time structure of the personal and social time: the internal (personal) time is seen as made of "right non-routine routines", whilst the external time, the "time of mankind", is linear, deterministic and, he thinks, shows a sort of human inertia oriented towards avoiding any change.

In Stefano and Giorgia the personal time creates a sort of "present bubble" that protects them from the external 'storm'.

Only Laura and Alessandro seem to perceive the need to maintain the nexus between the personal time of their experiences and social time. The realignment of their daily routines implies a dialogue with social changes and engagement with societal transformations. Alessandro, in particular, said:

"I hope that [this present time] has made us understand the fragility of our whole system and of our way of life [...]. One of the reasons why we sometimes think that everything can't change, is stable, destined to last, looking at it from a single point of view, is because, maybe, there has never been a moment like this in which the whole system has broken down; and so I hope that we can all become aware [...] of the fact that it doesn't necessarily have to go on as we have done until now; in my opinion we won't come out [from this moment] with the answers but already changing the point of view of millions of people is a big step."

Both Laura and Alessandro are very interested in social debate and, unlike Gabriele, they reveal a pro-active mood towards the possibility of acting on society and taking some agency in societal transformations. This pro-active mood was slightly more evident in Aldo's interview (one of the three students that we interviewed first and that we did not consider for the profiles). Aldo was the only student who explicitly mentioned the concept of "responsible citizen" as the nexus between personal and social realms and the way individuals can take agency to contribute to a better world. 
However, despite the references to society by Alessandro, Laura, Gabriele and Aldo, the students' profiles highlight that the personal dimension is, as we might expect, the most relevant aspect in the period of isolation. Lockdown gave students the opportunity to re-discover and cultivate interests that had been neglected due to lack of time, and to strengthen friendships and relations within the family. Furthermore, it also emerged that, for this group of talented students, ambition and trust in personal abilities were important ingredients in managing the crisis and exploiting the restored time. In our interviews we saw only a few signals about the need to reflect on the role of individuals as responsible citizens and active agents in this global, fragile and complex society. In accordance with the literature on future, dreams and hopes refer more to personal success than to a significant improvement of society as a whole. Even when society represents an important focus of attention, the perception that it can be changed and that each of us can be an agent of such changes seems, in general, faint. This is an important aspect where science education can insist and play a fundamental role.

\subsection{Appropriation and this contribution to the definition of present shock}

After the analysis of the time structures, we can now focus on the appropriation profiles that emerged from the application of appropriation markers as lenses to read the transcripts.

The most important result is that the application of markers resulted in five complete profiles of appropriation and one incomplete profile: all the markers were satisfied for five students out of six. Indeed only Stefano, the student who had the picture of time as a container, did not appear as an aware agent of his time and encountered a little difficulty in the metacognitive or reflective questions. His interview indeed looks like a collection/description of small activities or examples referring to his private life. He never answers a question at a level of meta-reflection and never refers to abstract concepts to reflect on time and the effects of this crisis. Instead, in his answers, he always refers to examples or small contingent cases related to his families and friends. For example, when he is asked to answer this question: are you currently feeling pressure or are you experiencing accelerated times coming from outside?, he answers as follows: then the most important thing concerns perhaps the work of my parents who, however, since ... [said slowly] that is, the work of my parents ... the work in general.

Stefano is also the student who least perceived any change. His daily rituals create a bubble that protects him from the external world and, in this bubble, there is neither directionality, nor any relationship with the accelerated time of social institutions that are running after the virus and trying to control it. The latter dimension is perceived as belonging to the adult realm.

In all the other cases, students appear not only able to express their core idea of time but they were also conscious that they were experiencing a special moment "that will be written in the history books" (Chiara) and that could be turned into something important for them. For example, Giorgia said:

"In this moment of suspension, the desire to be able to achieve something of personal success is even higher than before, so maybe it also gives that sense, that is, I self-influence my future."

Alessandro said:

"I was struck by the fact that in a very short time the pandemic has completely changed the cards a little bit in general... [...] my perception of "long time" has been a bit modified... in perceiving how an event [...] can also quickly enter and rewrite a page of history...".

The five complete appropriation profiles show that the conception of time outlined in the interview 
was the result of an articulated cognitive process. This process involved idiosyncratic and deep identity aspects (markers a and d), a special role ascribed to knowledge (marker b), awareness (marker c) and a special positioning within a social network (marker e).

As we reported in the introduction, within the future shock induced by the society of acceleration, alienation from time is argued by Rosa to be strictly interrelated with alienation from others and alienation from self. The co-presence of the five markers in most of the students' profiles shows that also the process of appropriation, the contrary of alienation, indicates deep connections between the appropriation of time (marker a), of self (markers $\mathrm{c}$ and $\mathrm{d}$ ) and the relations with others (marker e). In our case, also the role of disciplinary knowledge (marker b) is stressed as a fundamental component of this complex process that relates time appropriation with identity formation (appropriation of self and of others).

As sociology literature led us to expect, the process of time re-appropriation can be seen as an effect of the present shock. In fact, the interviews highlight that re-appropriation starts from personal daily-life rituals. Students feel a revived need to stay in the present of their daily experiences and to become agents of their personal daily life time. Before the pandemic, sociological studies stressed that social acceleration had diminished the time of everyday life to trivial and repetitive rituals that slowly disappeared from the attention of our societies. From our students' comments, it appears we are instead rediscovering daily time and its value. This concept of time is a form of defence against the virus, but it is also a way to save social cohesion and, for some students, to act as conscious witnesses of an important historical moment.

Moreover, all the students except Stefano, are exploiting their daily rituals to re-appropriate a deep sense of directionality that was lost in the era of future shock.

Giorgia is aware that, before the pandemic, we were in a moment of frenetic standstill, where change was somehow apparent. She feels the need to distinguish between "frenzy" and real development:

"Actually, I hope we understand the fact that this busy life didn't lead to so many developments in the end. [...] in this state, at least I have always felt it like this, everything was always the same, always constant over the years ... this situation and this block could give the opportunity for a change..."

For Giorgia, time has to be directional and change has to be real: the past has to provide hints, the present has to be exploited in order to become agent of one's own future. Lockdown was an opportunity to re-discover and strengthen the directionality of time and make effective plans for the future.

Also for Laura, the student who most perceived the present shock, lockdown pushed her to search for a new sense of directionality. Her personal organisation collapsed and important events that she perceived as milestones for her future were cancelled. Thus, she had to reinvent her daily routines simply to re-appropriate a sense of directionality. Directionality became, for Laura, a process of cultivating her passions and exploring society to recognise how and where she can nurture her interests, now and in the future.

Alessandro has consciously recognised the frantic arrest as a change, but not as a problem: an opportunity to seek a new sense of directionality given by immersing in one's own intellectual interests. Directionality for Alessandro, as for Laura, is offered by authentic intellectual thoughts or passions and by the sense they produce. For them both, directionality becomes lost in routines and experiences aimed solely at developing mere techniques. On the contrary, passions and sensemaking give directionality, turning experiences into Erfarunghen. Laura uses her passions also to project herself into the future. 
Gabriele is also looking for a non-routine routine. In his case, the search revolves around trying to "fill" time in the "right way". Unlike Alessandro and Laura, Gabriele is not experiencing any sense of deep change, and he is filling the day with the same interests, activities and reflections. He lives in a sort of bubble that is in continuous interaction with the outside world and from which he observes society that, at this specific moment, has become aware of critical issues that have in fact always existed but which are now impossible to ignore. The pandemic confirmed to Gabriele his idea about the dynamics that propel society: people are capable of looking only at their own interests, at what is important in that moment, neglecting, most of the time, the true sense of things. However he recognises that, for the world, the pandemic is a tragedy and, hence, he retains that "people" have to learn and find a sense of directionality: by looking at the past, people can extrapolate many teachings in order to achieve progress, better action in the future than in the present.

Chiara also perceives a sense of directionality in society but not in her private life. She manages the slowness and stillness of the present by immersing herself in bubbles of entertainment and imagination, but perceives the directionality of the historic moment, where people are working hard to obtain a cure for the virus and, in general, to manage the crisis. As we already stressed above, Chiara feels as though her daily life is totally detached from the directionality of society and, for her personal life, the only thing she can do is escape within fictional scenarios. This is the dimension of present shock that Chiara is experiencing: a clear separation between the velocity, priorities and actions of the world outside, and those of her daily life.

To sum up, the "appropriation" analysis of the interviews confirms some intuitions we had about the benefits of reading the present as a moment where people feel deeply the need to re-appropriate their time. Here we took the markers we identified for describing the appropriation of a physical concept like temperature, and extended their application to a more elusive concept like time. In the original approach the construct of appropriation allowed us to unpack how science learning could lead to a broader sense of learning and contribute to developing identity. Here, the application of our markers to time allowed us to recognise the time structures and rituals that underlie identity and that science learning should contribute to sustaining (for example, the ritual of sense making or rituals of skills development). Furthermore, the analysis contributed to outlining present shock in terms of revitalised importance ascribed to daily life rituals and in terms of discovery of a multifaceted sense of directionality: personal directionality given by a plan or by the search for sense, the collective directionality that society can find when huge events happen to upset the status quo.

\subsection{The role of science education}

The third axis we consider in comparing the profiles regards the role of science education. The data come from those parts of the profiles designed to answer the following questions of the analytic grid: Does the student use disciplinary/school knowledge (particularly, scientific knowledge) to manage their time (grounded in the disciplines)? What contribution does the interview provide to build an argument about the roles of science education and disciplinary knowledge in equippng the students with knowledge and competences to manage fast-changing space and time structures?

Firstly, the six students' profiles highlighted a polarised attitude toward the scientific knowledge acquired along their personal school path (school science). For three students out of six (Stefano, Chiara and Giorgia), school science represents a bubble in which they can feel at ease and that 
protects them from the toughness of the reality. For example, for Stefano, who is a very good student, studying science and math and solving scientific problems are sources of intellectual pleasure. Also, scientific disciplines in their application are a source of escape: they help him to manage internal times to eliminate anxiety by distracting from the external problems. Stefano does not use science as a key to read and interpret reality and the contingency. It creates "isolated bubbles" that, like a game, provide pleasure, enjoyment and social relationships. Also Chiara found in science a way to make sense of the present reality. In particular, the analysis of the epidemic curve from a mathematical perspective reassured and helped her to rationally manage the present. However, Chiara is aware that, in this moment, understanding the science behind the epidemic is important, but even more important is the need to personally manage the anxiety of the moment by escaping with her imagination. Even Giorgia finds a refuge in school science. Mathematics and physics are the subject matters that she prefers and their being, in her mind, a-historical and "certain" knowledge allows mathematics and physics school classes to restore a sense of "normality". Classes continue just like before the pandemic and the teacher does her best to "maintain normality" and do her classes as she did before lockdown. Giorgia thinks that this is possible because of the inner character of mathematics and physics as unchangeable, invariant, ahistorical and certain disciplines. Thanks to these aspects, mathematics and physics school classes give Giorgia a sense of peacefulness, even in such a strong moment of crisis.

Despite the interest of those students toward science, their engagement with the discipline is not a key for interpreting the current debates.

For the other three students (Gabriele, Alessandro and Laura), school science represents a baseline knowledge to be refined with hints and reflections coming from other sources and/or to be enriched with extra-curricular activities. School science can set out, somehow, an initial mindset concerning the kind of methods and discourses that belong to science.

For example, Gabriele holds scientific disciplines in high regard because they provide the basic knowledge that allows him to distinguish the person who holds the knowledge from the person who speaks to gain visibility or simply for the sake of speaking. School science allows him to decide who can be trusted or not, because it helps him to recognise when a discourse is well constructed and grounded.

Again, Alessandro recognises the importance of scientific thought in this time of emergency, and the role of scientific experts. However, he stressed that the study of scientific disciplines should provide not only knowledge - which may not be sufficient to enter into the merits of technical issues - but also the tools of scientific thought that allow him to move between the plurality of data and information and can act as a filter. Lastly, for Laura, physics and astrophysics are a deep passion on which she consciously builds her sense of time, by allowing her to project her imagination toward the future. Indeed, scientific methods and the science mindset are, for her, a way to rationally manage the present contingency and follow scientific controversies. However, this level of scientific awareness does not come from school science, which is completely removed from her mind, but from extra-curricular experiences.

We remind that the students selected for this study represent a sample of students chosen for bootstrapping the best information available about science education at school. All of them were highly motivated students, with a strong interest and passion for science, so much so that they had decided to attend a demanding extra-curricular course at the Department of Physics and Astronomy. Also because of the choice of sample for the study, the results have clearly revealed how much school science is missing an important educational opportunity in the pandemic era. Indeed, the patterns highlighted above, related to these two roles played by school science, can be 
seen as an expression of misalignment between the science taught at school and the science needed to deal with a "risk society" (Beck, 2000).

For these students, school science is completely detached from society. Science they are taught remains isolated in a school context: at best, it influences their ways of thinking about their personal career or creates a space for enjoyment and self-accomplishment. Their ideas of science do not provide them with effective lenses to interpret social dynamics triggered by the pandemic crisis. Even in the cases of students who refer to society and pose problems with a mindset that could be interpreted as scientific, they do not recognise them explicitly as skills developed at school.

Another idea that emerges from students' discourses is an epistemological belief that science heralds certain facts and indisputable truths that reassure and help them to make sense of the world. This could be ascribed to the almost-univocal focus of science curricula on Newtonian paradigm, where determinism, linearity and prediction are the keywords. The whole language of classical physics constructs an epistemological scaffolding to imagine the history and the future deterministically, as a linear progress toward an increasingly better world. Nevertheless, at the basis of the risk society there is a very different paradigm, i.e. the complexity paradigm, where different temporal patterns and models of causal explanation are conceptualised. As we already mentioned when we presented the project I SEE in the background, the science of complex systems could be a very rich source of concepts like scenarios, feedback, deterministic chaos, and agent, which could play crucial roles to open up new ways to conceive the scientific enterprise and its relationship with socially relevant themes like a pandemic. The concept of uncertainty could also be revalued in science education: not as something negative (lack-of-certainty) but as a concept that opens up a variety of possibilities for everyone's imagination. Another important concept that complexity has at its core and that could be valued through education is the idea of system. Indeed, the recognition of the multiple levels that constitute a system allow the students to make explicit these levels and their relationships also about real-life contexts (e.g. individual, familiar, local, national, global levels). A system can be investigated not only for its levels but also for the dimensions it covers and impacts (e.g. scientific, economic, societal, personal, environmental, health). Developing rich discussions in the classrooms about these aspects could be important to foster competences for analysis of complex issues. A STEM curriculum should include all these themes if we want to value science education as a way to prepare the young for this fast-changing society that appears more and more fragile and at risk.

\section{Discussion of the results and conclusions}

In this paper, we borrowed an idea from sociology and used it to reflect on the role that science education can play to enable the young to navigate a fast-changing society. We started from the notion of future shock as characterisation of the society of acceleration and observed that the pandemic has induced a different type of shock, which we define as "present shock". The aspects that we took into account for characterising this quick change is the fast disclosure of time structures that were invisible before the pandemic or diminished as trivial rituals. During a pandemic, the global time is accelerated by a natural phenomenon (the virus evolution), and we have become witnesses of the dynamics of social institutions (policy, health systems, educational systems, economics) trying to run as quickly as possible to slow down the speed of the epidemic . At the same time, our individual time is suspended in a bubble of present that has to be redefined in its inner rituals. 
On the basis of this idea, we carried out an empirical qualitative study to investigate how teenagers with a strong affinity for science are experiencing this moment of change and what can we learn from them, both to better define the idea of present shock and to reflect on the role of science education.

Our study focuses on six interviews and has a merely exploratory and piloting character: the type and number of the students makes the sample very particular but also, in our opinion, particularly rich for paving the way for further, wider and more specific, rounds of investigation.

We carried out a four-phase analysis of the six interviews. First we searched for the sensitising concept by navigating the whole corpus of data and we were able to identify that perception of future was not the way to encode the time structures that the students were enacting to manage the current situation. This phase led us to recognise, instead, the potential of our appropriation markers and we designed our analytic grid accordingly (Phase 2). The dichotomy between alienation from time and time re-appropriation became the crucial aspect for highlighting the difference between future shock (characteristic of the society of acceleration) and present shock (characteristic of the pandemic era).

The application of the appropriation markers led us to organise the data into six comparable profiles (Phase 3), which we compared along three different axes: i) pictures of time; ii) appropriation and its contribution to defining present shock; iii) the role attached by the students to science and its learning (Phase 4).

Each comparison led us to recognise inner but important aspects of students' discourse.

First of all, we saw that the macro-distinction between space and time as containers and space and time as relations, which characterises the debate on space and time in physics and philosophy, is always effective in capturing the main idea of time (and space). However, we also saw that we needed to refine the lens to restore, faithfully, the richness of students' discourse. We then used criteria taken from the sociology of time. These pushed us to focus on the nexus between the individual and social dimensions and, hence, on identity that is just situated in that nexus. Specifically, we were able to identify that the most important activities students carried out in their daily life could be interpreted as time rituals that the students enacted to maintain an unchanged sense of self (their intrinsic identity). In some cases, the maintenance of intrinsic identity implied simply allocating more time and priority to routines, activities or thoughts regarding authentic interests (like reading, training, or thinking). In other cases, it required a deep and, somehow, "dramatic" re-arrangement of daily rituals.

Independently of the individual differences, our analysis shows that, within moments of deep change, the time structures that contribute to forming identity become particularly evident. During a period of lockdown, each of us, more and more explicitly, deals with the need to realign selfperception as agent or receptors of change, and to adjust the ways we relate with others. This complex process requires the recruitment and application of a great deal of knowledge (diSessa, 2018), but also, we saw, specific time structures. Identity process is indeed regulated by rituals and routines that shape our "reflective project", made up of selective processes, exploration of options, and decision-making processes.

We can say that, thanks to the sociological lens, we were able to flesh out, in the words of Bakhtin, the chronotope of the process of identity rearrangement in the pandemic era. Chronotope derives

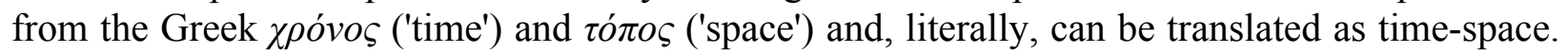
Bakhtin took this concept from relativity and, in particular, from Minkowski and used it metaphorically in literature. Bakhtin applied this construct to characterise each literary genre on the basis of the specific time and space configurations that emerged from the language and 
discourse.

In our case, we can also say that the chronotope that emerged from students' discourse revealed a special dialogue with oneself and others, mediated by knowledge. Specifically, we discovered that the "others" in students' discourse are friends, parents, teachers, and influencers. There is not that chorality that one could recognise as a sense of "collectivity", of "society". Indeed, a break and deep detachment appear in the personal and the social dimension: the personal chronotopes have rules, paces and rituals that appear completely different and detached from what the students perceive to be the social chronotope. Some of them use science to build and stay in their own chronotope bubble, protected from society.

Both personal chronotopes and their detachment from the social chronotope became even more evident through the analysis of the interviews along the axis of appropriation.

The application of our markers allowed us to argue that appropriation is in fact an effective counter-part of alienation. As alienation from time is strictly interrelated with alienation from others and alienation from self, also the process of time re-appropriation during the era of pandemic (marker a), is strictly related to the appropriation of self (markers c and d) and of the relations with others (marker e).

Moreover, and more specifically, the application of our markers to time allowed us to recognise two crucial elements in the time rituals that characterise the present shock which, we argued, can be related to identity: the renewed centrality of daily life rituals that had disappeared in the society of acceleration and the discovery of a multifaceted sense of directionality. Again, we saw here a detachment between a sense of personal directionality and of social directionality. As for personal directionality, we were surprised by the strong need some students felt to immerse in deep personal experiences and, in several cases, by the distance that emerges between this need and what the school required them to do.

This remark moves us on to the final results.

The school emerged from the interviews as a source of normative and soothing rituals that, even in a pandemic era, can offer certainties and a sense of normality.

For the students of our study, this is particularly true for the classes of mathematics and physics, i.e. the favourite subject matters of these students. They are seen either as sources of a-historical, unchangeable knowledge whose teaching cannot be affected even by so deep a crisis, or as a solid baseline on which personal or social interests can be nurtured by extra-curricular activities.

From this picture and from our analysis we see that science and STEM teaching could play definitively at least three more relevant roles.

Firstly, time and space are scientific themes that scholars from all other fields (sociology, philosophy, literature, policy...) use to interpret complex phenomena occurring in our global and fragile society. It is a missed opportunity that science and STEM curricula do not dedicate special attention to them, in terms of language, structures, and epistemologies elaborated to conceptualise and manage them. Time and space are intrinsic interdisciplinary themes that, if properly addressed, can turn knowledge into fundamental competencies for the 21 st century. In our previous projects, the debate on space and time was at the basis of the design of our materials on relativity and, in the project I SEE, we designed modules to point out the causal structures that science elaborated for managing uncertainty and the future in terms of forecasting or foresight. As we mentioned, the science of complex systems is an impressive source of fundamental concepts for consciously navigating the risk society. We are now working, within the project IDENTITIES, to refine these modules and exploit their interdisciplinary character (www.identitiesproject.eu).

Secondly, in this fast-changing society, it is more and more urgent that science education 
prioritises research studies aimed at evaluating its role in developing students' identities. This study shows that this also implicates revision of the curricula and teaching materials so as to boost specific rituals: training routines aimed ati developing technical skills but also, and mainly, rituals explicitly aimed at breaking down routines and fostering immersion in personal interests and thoughts. This operationally means designing materials and enacting teaching strategies that enable students to play with their own ideas and make them feel that their personal search for sense is legitimate and welcome also within the classroom culture. In our study on appropriation we argue how materials built on multidimensionality, multi-perspectiveness and longitudinality can support classroom dynamics that foster appropriation (Levrini, Levin, Fantini \& Tasquier, 2019). Now, we have unveiled new properties that dialogical chronotope should hold in order to foster identity formation. These properties link school and extra-curricular (home) activities, regarding the role of daily rituals and the centrality of a sense of directionality. These aspects can not only orient the revision of classroom activities but also shed light on the types of homework rituals that we can encourage.

Thirdly, school science has to thoroughly redefine its institutional role within society. Not only the knowledge but also the rituals that science teaching tends to boost seem to produce the effect of creating "bubbles". In a society characterised by a communication that enhances polarisation and echo chambers, the school system plays a crucial role and can make the difference. School must open up to society and enact processes that, whilst contributing to forming students as active and responsible citizens, also transform itself as an institution. This is the main direction that this study will follow in our next research studies within two Horizon 2020 projects: the SEAS project (https://www.seas.uio.no) and the recently-approved FEDORA project. We are indeed in an extraordinary period and must not miss the opportunity for deep social transformation toward a more human, rational, equal and sustainable society where there is space and time to take care of ourselves, others and the planet.

\section{References}

Adam, B. (1995). Timewatch: The Social Analysis of Time. Wiley. ISBN: 978-0-745-61461-8

Alexander, H. G. (1956). The Leibniz-Clarke Correspondence. Manchester: Manchester University Press.

Anderson, B. (2010). Preemption, precaution, preparedness: Anticipatory action and future geographies. Progress in Human Geography, 34, 777-798. doi: 10.1177/0309132510362600

Anfara, V. A., Brown, K. M., \& Mangione, T. L. (2002). Qualitative analysis on stage: Making the research process more public. Educational Researcher, 31(7), 28-38. doi: 10.3102/0013189x031007028

Bakhtin, M. (1981). Discourse in the novel (M. Holquist \& C. Emerson, Trans.). In M. Holquist (Ed.), The dialogic imagination (pp. 259-422). Austin: University of Texas Press.

Barelli, E., Branchetti, L., Tasquier, G., Albertazzi, L., \& Levrini, O. (2018). Science of Complex Systems and Citizenship Skills: A Pilot Study with Adult Citizens. EURASIA Journal of Mathematics, Science and Technology Education, 14(4), 1533-1545, DOI: 10.29333/ejmste/84841.

Bauman, Z. (2000). Liquid modernity. Cambridge, England: Polity Press.

Bauman, Z. (2001). The individualized society. Cambridge, England: Polity Press.

Beck, U. (2000). Risk Society Revisited: Theory, Politics and Research Programmes. In Adam, 
B., Beck, U. \& van Loon, J. (Eds.). The Risk Society and Beyond: Critical Issues for Social Theory. doi: 10.4135/9781446219539.n12

Branchetti, L., Cutler, M., Laherto, A., Levrini, O. Palmgren, E.K., Tasquier, G., \& Wilson, C. (2018). The I SEE project: An approach to futurize STEM education. Visions for Sustainability, 9: 10-26. doi:10.13135/2384-8677/2770, ISSN:2384-8677.

Carter, L., \& Smith, C. (2003). Re-Visioning Science Education from a Science Studies and Futures Perspective. Journal of Futures Studies, 7(4), 45-54.

Cavalli, A. (1985). Il tempo dei giovani. Bologna: Il Mulino.

Cook, J. (2016) Young adults' hopes for the long-term future: from re-enchantment with technology to faith in humanity. Journal of Youth Studies, 19(4), 517-532. doi: 10.1080/13676261.2015.1083959

Cuzzocrea, V., \& Mandich, G. (2016). Students' narratives of the future: Imagined mobilities as forms of youth agency? Journal of Youth Studies, 19(4), 552-567. doi: 10.1080/13676261.2015.1098773

diSessa, A.A. (2018). Identity and Knowledge. In T. G. Amin \& O. Levrini (Eds) (2918). Converging Perspectives on Conceptual Change. Mapping an Emerging Paradigm in the Learning Sciences, London and New York: Routlege, pp.297-304.

Erduran, S. (2020). Science Education in the Era of a Pandemic. Science \& Education, 29(2), 233235. doi: 10.1007/s11191-020-00122-w

Eurobarometer (2015). Public opinion on future innovations, science and technology, National report Italy, Eurobarometer Qualitative Study, June 2015.

Gee, J. P. (2001). Identity as an analytic lens for research in education. Review of Research in Education, 25, 99-125. doi: 10.2307/1167322

Giddens, A. (1991). Modernity and self-identity: Self and society in the late modern age. Stanford, CA: Stanford University Press. ISBN: 978-0745609324

Glaser, B., \& Strauss, A. (1967). The discovery of grounded theory. Hawthorne, NY: Aldine Publishing Company. ISBN: 978-0202302607

Greene, B. (2004). The Fabric of the Cosmos. New York: A.A. Knopf. ISBN: 978-0-375-412882

Heggli, G., Haukanes, H., \& Tjomsland, M. (2013). Fearing the future? Young people envisioning their working lives in the Czech Republic, Norway and Tunisia. Journal of Youth Studies, 16(7), 916-931. doi: 10.1080/13676261.2013.766682

Heikkilä, K., Nevala, T., Ahokas, I., Hyttinen, L., \& Ollila, J. (2017). Nuorten tulevaisuuskuvat 2067: Näkökulma suomalaisen yhteiskunnan kehittämiseksi. Turun Yliopisto. TUTU eJulkaisuja 6/2017. Available at https://www.utu.fi/fi/yksikot/ffrc/julkaisut/etutu/Documents/eTutu 6-2017.pdf

Kapon, S. (2017). Unpacking sensemaking. Science Education, 101 (1), https://doi.org/10.1002/sce.21248, 165-198.

Kapon, S., Laherto, A., \& Levrini, O. (2018). Disciplinary authenticity and personal relevance in school science. Science Education, DOI: 10.1002/sce.21458

Leccardi, C. (2003). Resisting "Acceleration Society". Constellations, 10(1), 34-41. doi: $10.1111 / 1467-8675.00310$

Leccardi, C. (2009). Sociologie del tempo. Soggetti e tempo nella società dell'accelerazione. Laterza. ISBN: 9788842088394

Levin, M., Levrini, O. \& Greeno, J. (2018). Unpacking the nexus between identity and conceptual change. Perspectives on an emerging research agenda. In T.G. Amin \& O. Levrini (Eds). 
Converging Perspectives on Conceptual Change. Mapping an Emerging Paradigm in the Learning Sciences, London and New York: Routlege, p. 313-333

Levrini O., \& Fantini P. (2013). Encountering Productive Forms of Complexity in Learning Modern Physics. Science \& Education, 22 (8), 1895-1910, DOI 10.1007/s11191-013-95874

Levrini O., Fantini P., Pecori B., Tasquier G., \& Levin, M. (2015). Defining and Operationalizing 'Appropriation' for Science Learning, Journal of the Learning Sciences, 24(1), 93-136, DOI: 10.1080/10508406.2014.928215

Levrini, O, Tasquier, G., Barelli, E., Laherto, A., Palmgren, E., Branchetti, L., \& Wilson, C. (2020). Recognition and operationalization of Future-Scaffolding Skills: Results from an empirical study of a teaching-learning module on climate change and future. Submitted to Science Education.

Levrini, O. (2002). The substantivalist view of spacetime proposed by Minkowski and its educational implications. Science \& Education, 11(6), 601-617.

Levrini, O. (2014). The Role of History and Philosophy in Research on Teaching and Learning of Relativity. In M. R. Matthews (ed.), International Handbook of Research in History, Philosophy and Science Teaching, Springer Netherlands, 157-181

Levrini, O., \& diSessa, A.A. (2008). How Students Learn from Multiple Contexts and Definitions: Proper Time as a Coordination Class. Physical Review Special Topics - Physics Education Research 4, 010107.

Levrini, O., Levin, M., \& Fantini, P. (2018). Personal, deeply affective, and aesthetic engagement with science content: when disciplinary learning becomes a vehicle for identity construction. In T.G. Amin \& O. Levrini (Eds). Converging Perspectives on Conceptual Change. Mapping an Emerging Paradigm in the Learning Sciences, London and New York: Routlege, p. 305-312.

Levrini, O., Levin, M., \& Fantini, P. (2020). Fostering Appropriation Through Designing for Multiple Access Points to a Multi-Dimensional Understanding of Physics. In B. W. Harrer, E. C. Sayre, L. Atkins Elliott (eds.), Focus Collection on Curriculum Development: Theory into Design, Physical Review - Physics Educational Research.

Levrini, O., Levin, M., Fantini, P., \& Tasquier, G. (2019). Orchestrating classroom discussions that foster appropriation, Science Education, DOI: 10.1002/sce.21475.

Levrini, O., Tasquier, G., Branchetti, L. \& Barelli, E. (2019). Developing future-scaffolding skills through science education, International Journal of Science Education, DOI: 10.1080/09500693.2019.1693080.

Newton, I. (1687). Philosophiae Naturalis Principia Mathematica.

Norgaard, K. M. (2011). Living in Denial: Climate Change, Emotions, and Everyday Life. Cambridge: MIT Press. ISBN: 978-0262515856

OECD (2018). The future of education and skills. Education 2030.

Pulcini, E. (2013). Care of the World. Fear, Responsibility and Justice in the Global Age. Springer. doi: 10.1007/978-94-007-4482-0.

Rickards, L., Ison, R., Fünfgeld, H., \& Wiseman, J. (2014). Opening and closing the future: Climate change, adaptation, and scenario planning. Environment and Planning C: Government and Policy, 32(4), 587-602. doi: 10.1068/c3204ed

Robinson, J., \& Godbey, G. (1999). Time for Life: The Surprising Ways Americans Use Their Time (2nd ed.). University Park, PA: Pennsylvania State University Press. ISBN: 9780271034263 
Rosa, H. (2009). Social Acceleration: Ethical and Political Consequences of a Desynchronized High-Speed Society. In H. Rosa \& W. E. Scheuerman (Eds.), High-speed society. Social acceleration, power and modernity. University Park, PA: Pennsylvania State University Press, 77-112.

Rosa, H. (2010). Alienation and Acceleration: Towards a Critical Theory of Late-Modern Temporality. NSU press. ISBN: 978-8787564144

Rosa, H. (2013). Social Acceleration: A New Theory of Modernity (New Directions in Critical Theory). Columbia University Press. ISBN: 978-0231148351

Sennett, R. (1998). Corrosion of Character: The Personal Consequences of Work in the New Capitalism. New York: W.W. Norton and Co. ISBN: 978-0393319873

SHRM (2019). 2019 State of the Workplace. Exploring the Impact of the Skills Gap and Employment-Based Immigration. Available at https://www.shrm.org/aboutshrm/Documents/SHRM\%20State\%20of\%20Workplace Bridging\%20the $\% 20$ Talent $\% 20$ Gap.pdf

Smolin, L. (1997). The Life of the Cosmos. Oxford University Press. ISBN: 978-0195126648

Tasquier G., Branchetti L., \& Levrini O. (2019) Frantic Standstill and Lack of Future: How Can Science Education Take Care of Students' Distopic Perceptions of Time?. In: McLoughlin E., Finlayson O., Erduran S., Childs P. (eds) Bridging Research and Practice in Science Education. Contributions from Science Education Research, vol 6. Springer, Cham, pp. 205224, DOI: 10.1007/978-3-030-17219-0_13.

Tasquier, G., Levrini, O., \& Dillon, J. (2016). Exploring Students' Epistemological Knowledge of Models and Modelling in Science: Results From a Teaching/Learning Experience on Climate Change. International Journal of Science Education 10.1080/09500693.2016.1148828.

Toffler, A., \& Toffler, H. (1970). Future Shock. New York: Random House. ISBN: 9780553277371

WGSI (2018). Empowering Canadians through Sustainable Development. Available at http://wgsi.org/sites/wgsi-live.pi.local/files/GenerationSDG-Blueprint-WGSI 2018.pdf 


\section{Annex 1 - Interview Protocol}

We are going through a very particular moment that is changing, among many other things, our daily lives, the ways to deal with our relationships and our perception of time.

\section{Section 1. Questions about the management of the present}

1. How do you concretely organize your day? What are the new, most difficult and most surprising aspects?

2. Is there anything you do with particular pleasure in this period? If so, what is it?

3. Is there anything in particular that scares or disorients you? If so, what is it?

4. Among the subjects you study at school, is there anything you pleasantly study (e.g. history, philosophy, science, literature, art, ...)?

5. Outside school, are there any activities you do with particular pleasure (e.g. readings, playing or listening music, following debates on on political/economic/social issues, ...)? Are there specific platforms/channels where you carry out these activities (e.g. social networks, television, associations, ...)?

6. Are you following debates that help you to interpret this particular historical moment? If so, which debates are you following, on which topics (e.g. health, political, philosophical, artistic, economic, psychological, social, artistic issues, ...)? Which platforms/channels do you use to follow them (e.g. social networks, television, associations, ...)?

7. Are there any experts you refer to? If so, what type of expert (e.g. teachers, scientists, medical/health personnel, politicians, journalists, writers, philosophers, communicators, friends, influencers ...)? Are there any expert persons in particular? If so, who?

8. Is there anythings you have learned in this particular period that you consider important for your personal, cultural and professional growth? If so, what?

9. More specifically, have you learned anything important about how science proceeds? If so, what? Have you learned anything about the relation between science, society and politics? If so, what?

10. Has your relationship of trust toward experts changed? If so, how?

11. On which dimensions of the problem do you tend to reflect more often (e.g. personal, emotional, scientific, political, ethical, ...)?

12. Do you think that your knowledge of science, mathematics and physics can play a role for understanding and managing this situation? If so, which role? If not, why?

\section{Section 2. Questions about the perception of time (present, past and future)}

13. Do you feel more like a present, past or future person? That is, to manage a moment of change, do you find greater stimulus/trust/refuge in the study of history and in drawing lessons from the past, in the management of present contingency or in imagining/dreaming future scenarios? Can you explain in what sense?

14. Has this crisis changed your perception of the "small" time of your daily life? If so, how? In particular, do you feel empty times, times of boredom, of waiting in your daily life? Do the days seem longer?

15. Do you feel acceleration times or pressures from the outside that influence your daily life?

16. Has this crisis changed your perception of the "big time" of history? If so, how? 
17. Do you think the world will emerge better or worse from this crisis? How?

18. Will the future of society benefit from this or should we expect a worsening compared to the future that was expected before the crisis? What do you mean?

19. Has this crisis changed your perception of the "mean" time of your education (e.g. choice of university, choice of professional field, choice of career, ...)?

20. We give you three different time horizons: the end of the lockdown, the end of school and end of university. How do you imagine yourself at these times? In which scenarios, or in which global social/political/cultural contexts, do you imagine yourself?

21. Do you think this moment of emergency will affect your future? What future? How?

22. Do you think this moment of emergency will affect society as a whole? If so, in which aspects?

23. How would you define your mood in front of this great change? 